\title{
EL ESTADO Y LOS PROBLEMAS DE LA VIDA MODERNA
}

I

Como es sabido, el concepto de sociedad es más extenso que el de Estado; el primero representa el género, el segundo una especie. La sociedad consiste en un vínculo que puede corresponder a varios fines, y en consecuencia asume diferentes estructuras (sociedad religiosa, familiares, económicas, profesionales, etcétera). El Estado se funda en el vínculo jurídico, y surge cuando este vínculo se afirma con una cierta preponderancia. No es, por otra parte, ni la primera ni la más vasta forma de sociedad, puesto que otras formas son anteriores a él, y algunas (por ejemplo: religiones, nacionalidad) pueden comprender un mayor número de individuos, pertenecientes a diversos Estados.

Para definir el concepto de Estado conviene partir entonces del de derecho. En su significado más general, el derecho es un criterio que determina una coordinación de las acciones entre varios sujetos, de modo que a una facultad o exigencia de una parte corresponde una obligación de la otra. Puesto que la vida humana no puede ser sino social (un caos absoluto no se ha verificado jamás y no es posible), aun en las formas primitivas de convivencia hay, al menos en embrión, un orden jurídico. Ubi homo, ibi societas; ubi societas, ibi jus. Pero esta noción formal no excluye que, en el ámbito del derecho, se distingan varios grados de perfección, hasta el supremo, que se identifica con el ideal de justicia.

\section{II}

En tanto que el derecho es coetáneo al género humano, el Estado se forma con un lento y laborioso proceso, a medida que el orden jurídico (primeramente fundado en el vínculo de sangre) se extiende y se consolida organizándose con un centro unitario propio, capaz de imponer la observancia de sus normas; de suerte que éstas aparecen como dependientes y determinadas por aquel centro, aun si de hecho han surgido, al menos en parte, independientemente de él.

En consecuencia, se puede definir el Estado como la unidad de un sistema jurídico que tiene un cierto grado de vigor positivo; o también como el sujeto (invisible pero real) del orden jurídico en el cual se realiza la comunidad de vida de un pueblo.

Pero es necesario advertir (análogamente a lo que ya se ha notado para el derecho) que con esto se define solamente el concepto formal del Estado, que lógicamente se aplica a todos los Estados existentes. Empero esta definición no significa que todos ellos sean igualmente sanos y adecuados a sus funciones. Por el elemento de la positividad, o sea de la fuerza preponderante, que está ínsito en su concepto, el Estado pertenece a las realidades de hecho; ahora bien, nuestra mente, por su naturaleza racional, puede y debe elevarse de la consideracićn de los hechos a la de los postulados ideales de la razón. Por consiguiente, es necesario admitir un ideal del Estado, como criterio superior (hiperfenoménico) para confrontar con él los datos empíricos que la historia y la experiencia nos muestran, y valorarlos precisamente con la medida de aquel criterio.

Sólo quien reniegue la validez trascendente de la ética, y confunda más o menos conscientemente la fuerza con la justicia, puede atribuir a cualquier Estado, o aun a! llamado Estado moderno, un valor absoluto, como "sociedad perfecta". La crítica filosófica disuelve semejante estadolatría, en tanto que asigna al Estado su propia misión, de cuyo cumplimiento depende la consagración de su autoridad. Tal misión se expresa con la palabra justicia; la cual evidentemente no va entendida como mandamiento arbitrario de quien posea el mayor poder, sino como conformidad a aquella ley, que puede ser violada pero no abolida, porque está impresa indeleblemente en 
la naturaleza humana. Y esta ley impone al Estado obrar para el bien común, en tutela de la dignidad del ser humano.

Ya Aristóteles, tratando de las varias constituciones de los Estados, distinguió netamente los gobiernos que obran por lo útil general o común (koinòn sumfèron) de los que en cambio obran por lo útil propio o particular (idion sumfèron) : esto es, entre las formas sanas y las corrompidas o degeneradas. Esta distinción crítica fue acogida y desarrollada por la filosofía posterior, en especial por la Escolástica, que todavía ilustró el concepto del bonum commune, como fin del Estado; sin perder de vista jamás la posibilidad de errores y degeneraciones, de los cuales la historia de todo tiempo muestra desgraciadamente numerosos y patentes ejemplos.

\section{II |}

Importa observar que la vida de los Estados está sujeta a variadas vicisitudes. Si bien la palabra Estado parecería indicar una cierta estabilidad, la verdad es que todo Estado está constreñido a un continuo, dinámico y complejo trabajo, por el cambio de las circunstancias, de las necesidades y de las opiniones de sus componentes, además de sus relaciones con el mundo externo. Debe ante todo mantener el orden jurídico, pues si no fuese capaz de esto, perecería, y en su lugar surgiría por necesidad otra formación politica. Pero el mantenimiento del orden jurídico no es posible sin una gradual renovación de éste, que con frecuencia da lugar a contrastes y a crisis. En tanto, debe ser proseguida sin treguas la lucha contra el entuerto, esto es, la acción defensiva y reparadora donde el derecho sancionado por las normas vigentes sea amenazado o lesionado.

Son bastante conocidas las grandes crisis que han turbado profundamente la vida de los Estados en tiempos antiguos y recientes, especialmente con las Ilamadas guerras civiles. Pero, en sentido amplio, puede decirse que una cierta crisis, si bien latente y exenta de manifestaciones violentas, está ínsita en la naturaleza misma del Estado; de lo que no es difícil discernir las causas.

El derecho en todas sus expresiones es, sin duda, un producto del espíritu humano; y todo hombre es naturalmente una fuente de derecho, en cuanto puede traer de sí, de su conciencia, afirmaciones juridicas, aunque sean rudimentarias e imperfectas; afirmaciones que normalmente corresponden a las del sistema vigente, pero también pueden ser diferentes y divergentes de ellas. La espontánea productividad jurídica de los individuos y de sus agrupamientos se vuelve evidente en el hecho indicado hace poco, que normas reguladoras de las relaciones de convivencia se forman aun antes del surgimiento del Estado; y la impronta de tales orígenes se conserva aun cuando aquellas formaciones espontáneas (por ejemplo: la unidad familiar) son incluidas en el orden estatal, y algunas veces modificadas en él con nuevas reglas.

Aquella productividad natural se ejercita aún en el ámbito del Estado, puesto que nuevos agrupamientos sociales, para los más variados fines, germinan de continuo, y toda sociedad (es preciso recordarlo) tiende a darse un derecho propio, en tanto que ya en su surgimiento no puede carecer al menos de un inicio de ordenamiento jurídico: ya sea que lo derive inmediatamente de las leyes del Estado, ya sea que intente construirlo de modo más o menos autónomo. La historia del derecho nos ofrece innumerables ejemplos en el segundo de los casos. Para indicar aquí solamente algunos, comenzando por el más conocido e importante, recordemos que la iglesia católica se ha dado un ordenamiento jurídico propio extraestatal y superestatal, permaneciendo unida a los Estados sólo con relaciones genéricas; y esto también puede decirse, guardadas las debidas proporciones, de otras organizaciones religiosas. Además, se ha formado ab antiquo una comunidad jurídica internacional (que no se confunde con la Organización de las Naciones Unidas ni con otra institución análoga) es decir, una serie de normas muy elementales, independientes de cualquier deliberación o acuerdo de carácter estatal, pero teniendo sin embargo una cierta existencia positiva en cuanto son observadas generalmente como costumbres, para hacer posibles así relaciones y cambios entre varios pueblos aun a falta de leyes y tratados.

Atención particular merece el fenómeno de las asociaciones o corporaciones de artes y oficios, que de varios modos tanto en siglos pasados como en el nuestro, han elaborado un derecho propio en el seno del Estado. Es conocida la importancia que los estatutos de tales organizaciones tuvieron en la vida jurídica del medievo, habiendo sido reconocidas frecuentemente por los poderes públicos y gozado efectivamente, una autoridad no menor a la de los estatutos municipales. Baste recordar, por ejemplo, que el comercio marítimo fue regulado por ordenamientos elaborados por los navegantes en forma de usos, y después codificados como en la famosa Mesa Amalfitana. En nuestra época, asociaciones de trabajadores se ponen frecuentemente en antagonismo con los órganos del Estado, suscitando así problemas políticos de no poca importancia. 
La libertad de asociación, no puede, en general, ser negada por el Estado; y la prohibición (sancionada por una ley en el tiempo de la Revolución Francesa) de cualquiera organización corporativa, para admitir únicamente la relación entre Estado y ciudadano sin las formas intermedias de la sociedad, fue ciertamente un error: puesto que el espíritu sociable ínsito en la misma naturaleza humana se explica por una serie de grados, ascendiendo del individuo al Estado; y las excesivas restricciones de esta tendencia natural no pudieron jamás durar mucho tiempo, o tuvieron por solo efecto cambiar las sociedades manifiestas en secretas.

Por otra parte, el Estado tiende por su naturaleza a concentrar en sí, para constituirlas en sistema coherente, todas las formaciones jurídicas que se producen en su seno. Por eso también las normas que se vienen elaborando con proceso espontáneo por las asociaciones sindicales o corporativas pueden y deben ser acogidas e insertas, aunque frecuentemente no sin modificaciones y adaptaciones, en la compaginación del Estado, siempre que no alteren aquellos principios fundamentales que son las razones esenciales de la existencia del Estado mismo: esto es, la garantía del orden público y de la paz social.

Por consiguiente, las actividades y las energías normativas de estas entidades deben conciliarse y armonizarse con las expresiones directas de la soberanía estatal. Esto requiere un esfuerzo reciproco de comprensión y de adecuación, sin lo cual serian inevitables graves perturbaciones en la vida de la sociedad y del Estado.

El hecho de pertenecer a una clase particular no debe, empero, extinguir jamás ni exceder el "sentido del Estado", así como éste no puede suprimir nuestra dependencia con la humanidad.

\section{V}

Otro fenómeno que especialmente en los tiempos modernos (aun teniendo orígenes antiguos) ha intervenido para complicar la vida del Estado y frecuentemente para agravar la crisis de éste, es la división de los ciudadanos en diversos partidos. Mientras éstos se limiten a defender ideales y programas, reconociendo y respetando lealmente la autoridad de los órganos constitucionales del Estado (como sucede típicamente en la Gran Bretaña), la formación y la acción de los partidos responde sin duda a un derecho fundamental de los ciudadanos, y puede realmente ayudar a estimular y controlar la actividad de aquellos órganos. Pero cuando, como ha sucedido en Italia y también en otros países, se organizan parti- dos que propugnan abiertamente la subversión del Estado, éste no puede dejar de defenderse, imponiendo en formas legales límites y restricciones a la actividad de aquellas organizaciones; pues si es "Estado de justicia", defendiéndose a si mismo defiende en realidad a la justicia. Nótese que en la vida actual, estando multiplicadas las relaciones internacionales, aun los partidos existentes en un Estado se coligan frecuentemente con los que en otros Estados sostienen ideas similares o afines, y en algún caso se someten directamente a un partido extranjero análogo; y es superfluo decir con cuénto peligro para las instituciones del Estado, si se trata de un partido subversivo.

En la práctica, la fuerza de algunos partidos ha devenido tan grande en Italia, que ejercen un influjo predominante sobre los mismos órganos estatales, perjudicando la función asignada a ellos por las leyes constitucionales. Se advierten cada día más los perniciosos efectos de tal procedimiento, y se invocan normas precisas que impidan los abusos de la llamada pariidocracia.

Varias son las causas de este inquietante fenómeno; y la más general es sin duda un relajamiento moral que ha debilitado y desviado en gran parte del pueblo la conciencia de los deberes hacia la patria y el culto de los más santos ideales, haciendo abrazar, en cambio, bajas y falsas doctrinas materialistas y egoistas. Pero hay también una causa más precisa y directa del presente decaimiento de la costumbre política: esto es, la aplicación mecánica e irracional del principio de la universalidad del sufragio. La adopción de este principio, en abstracto justo pero entendido injustamente como desconocimiento total de las diferencias de capacidad entre las varias personas, ha modificado profundamente, hace algunos decenios, las bases de la vida política del Esiado. Antes que a un cuerpo electoral calificado, la elección de los representantes de la nación, y por consiguiente, en definitiva, los destinos de ella, han estado confiados a una enorme masa indiferenciada, en la cual los hombres más capaces por mayor experiencia y cultura han estado, por así decirlo, sumergidos. Esto ha tenido como consecuencia la formación de partidos con gran número de adherentes dominados por unos cuantos profesionales de la política y vinculados por una disciplina rígida. Aquella reforma que entendía consagrar un derecho individual de libertad ha producido en cambio una nueva clase de servidumbre: en amplios estratos de la población el sentido de la grey ha venido sustituyendo al sentido de la individualidad. $Y$ no es sorprendente que en tal estado de cosas la predicación del odio haya encontrado frecuentemente mejor terreno que la del amor. 
Es necesario por tanto que se multipliquen los esfuerzos para educar e iluminar al pueblo, aconsejando a los dudosos, enseñando a los ignorantes, confutando los errores, indicando y propagando las verdades esenciales de la ética, promoviendo en suma, con las palabras y con los actos, un resaneamiento de la sociedad para el bien común.

Por lo que concierne al sistema electoral, nada vedaría que, manteniendo firme el principio del sufragio universal, se perfeccionase la aplicacićn de éste, atribuyendo mayor peso al voto de los que hayan alcanzado una cierta edad o una preparación intelectual, aun sin excluir del electorado a los demás. Se podria, por ejemplo, atribuir una cuo:a (pongamos, del cuarenta por ciento), sobre el total de la representación por elegir, al voto de las personas provistas de un título de estudio (por ejemplo: una licencia de escuela media $u$ otro título equivalente), cualquiera que sea la edad de aquéllas; repartiendo la cuota remanente entre las otras personas, según hayan o no alcanzado una cierta edad (por ejemplo: de treinta o treinta y cinco años), de modo que sea reconocido un mayor valor al voto de los que, aunque privados de títulos de estudio, hayan adquirido aquella experiencia que se obtiene precisamente con el avance de la edad. Pero no es necesario aquí detenernos todavía sobre este problema, que podría quizás comportar también otras soluciones, las cuales, empero, deberían siempre inspirarse en el bien común, con el respeto de los derechos de todos.

\section{V}

Entre los entes sociales que viven en el seno del Estado, hay uno que por su gran importancia y por su singular naturaleza requiere una consideración especial: esto es, la iglesia. Ella tiene como fin último la salvación de las almas en un orden ultraterreno, pero para este mismo fin, da normas a toda la vida humana. Por otra parie, el Estado, sobre la base y en la forma del derecho, debe proteger la persona humana (que no es sólo corpórea, sino también espiritual), garantizando un cierto orden en todas las manifestaciones de su actividad. De aquí lo inevitable de un encuentro y la posibilidad de contrastes entre las dos autoridades, y además, de crisis de conciencia en los individuos que dependen de ambas. Todos saben cómo tales contrastes no sólo alcanzaron disputas doctrinales, sino turbaron frecuentemente y por largo tiempo la vida de los pueblos.

En consecuencia, es sumamente deseable que se establezca una coordinación entre las esferas de compe- tencia de los dos poderes: una coordinación que no puede consistir en una simple delimitación, como si se tratase de señalar confines territoriales, sino debe comprender también una concordancia real de acción. Los acuerdos lateranenses de 1929, que pusieron término a la disidencia entre la iglesia católica y el Estado italiano, fueron inspirados por un sentimiento de respeto recíproco y por un intento común de colaboración, salvando las diversas características de los dos entes, declarados, aun por la Constitución sucesiva del Estado italiano, "cada uno en el propio orden, independientes y soberanos". Pero los mismos acuerdos determinan normas pertinentes a uno y a otro orden a la par, y también, para algunas materias, una atribución de competencia mediante un reenvío, a veces del orden jurídico del Estado al de la iglesia, a veces también inversamente; de modo que una misma institución deviene válida, efectivamente, para ambos, y los mismos individuos pueden cumplir a un tiempo sus deberes de cristianos y de ciudadanos. Así, por ejemplo, la legislación italiana ha reconocido la plena validez del matrimonio celebrado ante un ministro del culto católico según los cánones de la iglesia, salvo obligación del envío a la municipalidad para la transcripción del acto en los registros de estado civil. Bajo ciertas condiciones, es reconocida también la validez de los matrimonios celebrados ante los ministros de los otros cultos admitidos en el Estado, en homenaje al principio de la libertad en materia de fe religiosa, sancionado por la constitución; en tanto que, de conformidad con el mismo principio, ha quedado en vigor la institución del matrimonio civil.

Al contrario, en materia penal el derecho de la iglesia desde antes de los acuerdos lateranenses se ha referido frecuentemente al estatal para los delitos que no tienen carácter exclusivamente religioso (Véase Codex iuris canonici, cán. 2198). Se puede recordar también que en el Estado de la Ciudad del Vaticano han sido declaradas aplicables las leyes penales italianas.

Está fuera de duda que los principios de la ética cristiana inspiran e informan toda la civilización moderna, y son aceptados particularmente por la población italiana, que en la casi totalidad profesa la religión católica; en tanto que también las minorías no-católicas reconocen en sustancia los mismos principios. Según el Concordato lateranense, Italia considera fundamento y coronamiento de la instrucción pública la enseñanza de la doctrina cristiana de acuerdo con la versión recibida de la tradición católica; y por eso es impartida en las escuelas públicas, dándose sin embargo facultad a los padres 
- a quienes los representen, de solicitar exoneración a dichos cursos.

El Estado tiene entre sus fines el de educar e instruir a la juventud, completando el derecho y el deber de los padres respecto a sus propios hijos. Por esto debe instituir escuelas abiertas a todos, siendo la instrucción obligatoria de impartirse al menos por ocho años, por norma de la Constitución. Pero no existe sobre esto una capacidad exclusiva del Estado; antes bien, es expresamente reconocido por la misma Constitución que entidades y particulares tienen el derecho de abrir escuelas e institutos de educación. Normas especiales son establecidas por el Concordato lateranense por lo que concierne a las escuelas instituidas por entes eclesiásticos.

A las escuelas privadas puede ser concedida la paridad con las públicas; pero para la validez de los diplomas y el ejercicio profesional, está prescrito un examen por el Estado, aplicándose esto también a las escuelas sostenidas por sociedades eclesiásticas o religiosas, salvo las normas especiales concordatarias.

El Estado no está obligado jurídicamente a subsidiar escuelas privadas: sin embargo, es indudable ( $y$ esto fue aclarado expresamente en los trabajos de la Asamblea Constituyente) que el Estado puede legítimamente conceder subsidios, y es más bien deseable que los conceda en medida suficiente, manteniendo siempre la vigilancia debida a fin de que aquellas escuelas cumplan rectamente su función.

Sobre este punto, y también sobre otros de esta materia compleja, numerosos problemas prácticos de no fácil solución surgen frecuentemente; ya sea porque los medios existentes son en general demasiado escasos en comparación con los fines indicados, ya sea también porque sobre el uso de aquellos medios se manifiestan divergencias más o menos graves de ideas y de intereses. Aun sobre la interpretación del Concordato lateranense pueden surgir dificultades; y esta posibilidad está prevista por el mismo Concordato, que sabiamente dispone que en tal caso "la Santa Sede e Italia procederán de común inteligencia a una solución amigable".

Análogamente, un espíritu de conciliación, con intención de superar los contrastes, debería prevalecer en todas las disputas sobre los problemas de la vida social; y aquí nos referimos especialmente a las disensiones en materia de educación e instrucción.

Nadie ignora que en Italia, como en otros países, una parte no pequeña del pueblo sufre no sólo por la triste condición económica, sino también, y quizas todavía más, por la falta de una sana cultura moral, y por ello se aban- dona fácilmente a supersticiones y a pasiones desordenadas. Es deber de todos los hombres ilustrados esmerarse e intensificar los esfuerzos para combatir estos males: la llaga vergonzosa del analfabetismo, las falsas doctrinas que inquinan las conciencias, las ásperas discordias que conturban la vida de la sociedad y del Estado, impidiendo o disminuyendo, con daño de todos, los progresos civiles.

\section{VI}

El Estado no debe constituir algo cerrado. Por muy importantes que sean los vínculos que lo ligan a los individuos que lo componen, relaciones internacionales de varias especies (morales, religiosas, intelectuales, económicas) se iniciaron ya en tiempos antiguos y se desarrollaron progresivamente, asumiendo aun formas jurídicas más o menos precisas. La unidad del género humano, intuida en algún modo hasta por los principios del pensamiento filosófico, tuvo la más alta consagración en el cristianismo, que afirmó la fraternidad de todos los hombres. Pero una verdadera y perfecta societas humani generis, si bien quedó siempre como un postulado ideal, no se ha constituido todavia positivamente; y la multiplicidad de las diversas organizaciones políticas ha dado lugar, en toda la historia humana, a frecuentes conflictos, devenidos siempre más mortíferos por el continuo perfeccionamiento de los instrumentos bélicos. Se ha llegado hoy a tal punto, que la existencia de pueblos enteros, por no decir de toda la humanidad, es puesta en peligro por la eventualidad de una guerra, mientras se invoca la paz por todas partes.

Sostener la renuncia a toda defensa, con un desarme unilateral, sería un error, porque esto equivaldría a alentar los propósitos agresivos de quien no estuviese dispuesto a igual desarme. Es necesario, sin embargo, apoyar sin descanso la paz, condenar cualquier programa de conquistas militares $y$, según la fórmula de la Constitución italiana, "repudiar la guerra como medio de resolución de las controversias internacionales". La guerra es legítima sólo en el caso de una inmediata necesidad de defensa. La idea de la paz, por otra parte, no puede separarse de la de justicia (Justitia et pax osculatae sunt, como dicen los Salmos). Esto no significa que sea lícito el recurso a la guerra para oponerse a cualquiera injusticia y sostener cualquier derecho, en cuyo caso se multiplicarían las causas de guerra, poniendo a riesgo los derechos verdaderamente fundamentales; puesto que toda guerra ocasiona una perturbación profunda del orden jurídico en general, y ninguna guerra puede ofrecer una garantía de conducir a una paz justa. 
Es necesario que se desenvuelva aun en este campo una sana obra educativa, no ya en el sentido de inducir a una vil ignavia, sino al contrario, para exhortar a los jóvenes al cumplimiento gustoso de sus obligaciones militares $y$, en general, para promover una acción enérgica y valerosa en la lucha contra los vicios y las plagas que corrompen a la sociedad actual. Se requiere para esto una virtud no menos valerosa que la que puede desplegarse en las batallas; puesto que también esta lucha es una especie de milicia, como observó ya Lactancio: justi militia est in ipsa justitia.

Debe cumplirse al mismo tiempo todo esfuerzo razonable a fin de que se extiendan y consoliden las relaciones pacíficas y amigables entre la nación propia y las otras, favoreciendo aquel proceso de unificación moral, que corresponde a la naturaleza común del género humano. La concordia y no la discordia debe tenerse como mira, tanto por lo que respecta a las relaciones internas, como también cuanto concierne a las relaciones iniernacionales. Justo es que se exalten las gestas de la propia patria; pero es necesario evitar las infatuadas vanaglorias y rendir justicia también a la obra de los extranjeros. No deben alimentarse facciosamente los recuerdos de pasadas guerras y contiendas, perpetuando de tal modo los antagonismos, sino más bien sobre aquéllos deben ponerse las bases para una paz nueva y fecunda.

Estos conceptos deberían inspirar especialmente los programas didácticos, en los caules convendría dar un lugar más amplio a las máximas de la caridad y de la justicia, en todas sus aplicaciones a los problemas de la vida moderna. Puesto que aquellas máximas no son y no pueden ser refutadas por ningún pueblo civilizado, o que aspire a insertarse en un orden de civilización, no debería ser imposible la compilación de un texto único, adoptable en las escuelas de todos los Estados. De la idea de justicia universalmente entendida, se sigue el debido respeto a la dignidad y al valor de la persona; los derechos naturales del hombre y del ciudadano deberían ser por esto claramente afirmados como máximas de razón; y partiendo de la idea de caridad, universalmente entendida ella también, todas las virtudes humanas deberian ser sumariamente ilustradas, para demostrar su función tanto respecto al bien individual como al social.

No están, quizás, todavía maduros los tiempos para una codificacićn jurídica que rija efectivamente a toda la humanidad; pero bien puede intentarse una codificación moral. $Y$ no estarán jamás perdidos los esfuerzos que se hagan para este fin.
Tambien en el campo del derecho hay, por lo demás, innegablemente una tendencia a una coordinación y a una unificación mundial; y si la meta está todavía lejana, no por esto debe desconocerse la importancia de los pasos dados hacia ella, en tanto que se deben dar otros, con la firme fe de que será alcanzada.

inútil recordar aquí las numerosas organizaciones internacionales, que han aparecido especialmente en nuestro siglo, hasta la Organización de las Naciones Unidas, que comprende la mayor parte de los Estados existentes. Pero no es de callarse que también esta organización no es ciertamente una sociedad perfecta; y su principal defecto consiste en no haberse atenido a su mismo programa. Si bien ha afirmado solemnemente en su Estatuto y después, más ampliamente, en la Declaración universal de los derechos humanos, su intento de reafirmar la fe en los derechos fundamentales de la persona humana, no ha dudado, empero, en acoger en su seno Estados que desconocen manifiestamente tales derechos, tanto en el propio orden interno, como en las relaciones con los otros Estados. Además, mientras en su Estatuto ha afirmado el principio de la igualdad de todos sus miembros, ha acordado una posición de privilegio a algunos Estados, poniendo a los otros en una condición de inferioridad permanente; contradicción tanto más grave e injusta, cuanto que entre los Estados privilegiados hay alguno que no respeta enteramente los derechos humanos, mientras en la segunda categoría hay otros que sí los respetan.

Es verdad que, no obstante sus imperfecciones, la Organización de las Naciones Unidas ha podido rendir algún servicio a la causa de la paz; por esto es de auspiciar, que ella viva y, corrigiendo posiblemente su estructura, ofrezca una acción más adecuada a sus altos fines.

Pero conviene todavía insistir sobre esto, pues la paz es tanto más segura cuanto más reposa sobre la justicia, y tener presente que las organizaciones internacionales son tanto más sólidas y eficaces cuanto más homogéneos son los principios sobre los cuales se fundan. Por eso, rectamente, han sido concertados acuerdos entre Estados cuyas constituciones contienen garantías de la libertad, y se proponen la defensa de ésta contra los peligros que la amenazan. Las organizaciones surgidas de tales acuerdos, si bien comprenden un número bastante menor de Estados, son en realidad no menos importantes que la de las Naciones Unidas, y deberian ser sostenidas unánimemente por los pueblos representados en ellas.

Corresponde al Estado promover, tanto mediante convenciones con otros Estados como con proveimientos de 
orden interno, el incremento de las comunicaciones internacionales, aún por el progreso de la cultura. $Y$ a la obra del Estado debe corresponder la de los individuos, en especial de los que están mayormente calificados para la actividad del espíritu. Deben ser removidas las barreras que se oponen a las relaciones intelectuales y a la difusión de las obras del pensamiento. Para el mismo fin, deben ser facilitadas las reuniones y las asociaciones internacionales entre los cultivadores de una misma ciencia, como también los viajes y las estancias en países extranjeros con miras de estudio, con subsidios oportunos especialmente en favor de los jóvenes mejor preparados e idóneos.

Se procederá de tal modo a la formación de aquella república universal del pensamiento, que es una meta ideal a la que tiende por su naturaleza el pensamiento mismo. $Y$ se favorecerá con esto también el progreso hacia una verdadera y perfecta sociełas humani generis, en la cual, según las palabras de Dante, genus humanum liberum in pacis tranquillitate quiescat.

\section{VII}

Las falsas doctrinas que atribuian al Estado un poder absolutamente arbitrario han sido justamente refutadas $y$ repelidas por la sana filosofía del derecho; lo que no quita que ellas afloren todavía en ciertas tesis seudofilosóficas, puesto que, como observaba ya Cicerón, nihil tam absurde dici potest, quod non dicatur ab aliquo philosophorum.

La verdad es que la autoridad del Estado está determinada por una ley natural (reflejo, según la teología, de la lex aeterna), que le asigna una misión propia y limita consiguientemente su esiera de competencia. El Estado racionalmente concebido es el punto ideal de convergencia de los derechos individuales, que son lógicamente anteriores a él, aun si de él esperan el reconocimiento y la confirmación positiva. En todo momento de su acción, el Estado no puede precindir de aquel presupuesto, sin privarse del título que justifica su existencia; puesio que precisamente la protección de los derechos naturales del ser humano es la razón primera e inmanente de su actividad, y la condición esencial de su legítima autoridad sobre los individuos.

Esto no significa que el Estado deba solamente impepedir las ofensas de los derechos individuales (que sea casi simplemente, como fue dicho, "Estado gendarme" o "guardián nocturno"); es necesario antes bien que desarrolle una amplísima actividad para promover el bien común, pero siempre sobre un fundamento jurídico y bajo la forma del derecho. En este sentido el Estado moderno en los pueblos más civilizados se califica como "Estado de derecho" o, como quizás se podría decir mejor, "Estado de justicia".

El Estado no puede, en suma, obrar legitimamente sino como órgano de la igual autonomía de sus componentes; y este principio no podría ser abolido ni por un acto de imperio del poder central, ni por una deliberación de asambleas o de grupos de individuos. Un error funesto es el de creer que todo pueda ser, en el Estado, objeto de válidas deliberaciones por obra de una mayoria cualquiera. Hay, desgraciadamente, una tendencia malsana de las mayorías a sacrificar a las minorías; como hay una tendencia egoísta de los más fuertes a oprimir a los débiles. Pero precisamente contra tal tendencia está, en sus bases fundamentales, el derecho. $Y$ el derecho de un hombre es tan sagrado como el de millones de hombres.

La sujeción del individuo al poder público no es por consiguiente incondicionada. Al deber de obediencia que incumbe en general a los ciudadanos se compagina, en un Estado ordenado según justicia, la facultad de los mismos ciudadanos de concurrir a la formación de las leyes y de exigir su observancia, aun procediendo por vías judiciales contra los abusos eventuales de los órganos del Estado. En este concepto de obligación bilateral está el núcleo de verdad de la teoría, con frecuencia formulada inexactamente, del contrato social.

Si el Estado viene a menos en su misión y viola la ley de la justicia, abusando de aquel poder preponderante que basta, en rigor, para dar a sus determinaciones el carácter de una legalidad positiva, o sea a hacerlas vigentes efectivamente; si descuida u oprime a los más débiles, y antepone intereses particulares al bien común; si desprecia o amenaza los derechos más arraigados en la conciencia humana, como por ejemplo la libertad religiosa; y si son vanos los llamados para las reformas necesarias, surge el problema de la legitimidad de la resistencia $y$, en fin, también de la revolución. Problema entre los más arduos de la ciencia política y de la filosofía del derecho, que en la vida de los pueblos, como todos saben, se ha traducido en crisis muy graves y sangrientas.

Es necesario aclarar previamente que no toda aspiración a lo mejor que encuentre obstáculo en las leyes vigentes, es motivo válido para rehusar obediencia a éstas. La estabilidad del orden jurídico tiene por si misma un cierto valor ético. Por esto fue reputado siempre noble el sacrificio de Sócrates, quien quiso sufrir una sentencia 
inicua, antes que dar a sus discípulos y conciudadanos el peligroso ejemplo de despreciar las leyes patrias. Análogamente, más tarde, la filosofía escolástica, por obra de su mayor representante, Santo Tomás de Aquino, enseñó a obedecer aun a las leyes no conformes con el bonum commune, propter, vitandum scandalum vel turbationem. Sólo en los casos de violación de las leyes naturales y divinas sería legítima una desobediencia o una reacción, no con el fin de destruir, sino de reafirmar el derecho: aquel derecho absoluto y eterno, ya violado $e$ infringido, en hipótesis, por leyes falsas y perversas.

Sería empero injustificable el querer obtener por vía de revolución lo que fuese obtenible por vía de reforma.

No se debe olvidar qué motivos bastante variados pueden conducir a impugnar el orden jurídico establecido: tanto la aspiracićn a una justicia más alta, como el ansia egoísta de sustraerse a los propios deberes. No raras veces en los movimientos revolucionarios se ha abusado del nombre sacro de la justicia para cubrir intereses particulares y desahogar bajas pasiones.

Sería erróneo, por tanto, considerar a priori todas las revoluciones como instrumentos de progreso jurídico; se debe más bien admitir la posibilidad de revoluciones regresivas, junto a las progresivas. $Y$ es útil observar que con frecuencia las revoluciones más profundas y fecundas fueron también las menos violentas.

Importa notar además que si un movimiento revolucionario falla y, por ende, no alcanza a instaurar un orden nuevo y más justo, la tentativa es calificada como un delito grave y tiene como efecto provocar una aspereza (vale decir, en los más de los casos, un empeoramiento) del régimen existente.
Por todas estas razones, es oportuno poner en guardia especialmente a los espíritus juveniles contra la ilusión de las ideologías revolucionarias.

Para promover la corrección de las leyes defectuosas e injustas sin el uso de la violencia, existen, al menos en los Estados donde es admitida la libre discusión, varios medios de no dudosa eficacia; y una función importante corresponde en este propósito, además que a los cuerpos legislativos y administrativos, a los órganos judiciales, que no son instrumentos mecánicos ligados a la letra de las leyes, sino que deben interpretar su espiritu, para extraer de ellas lo más que sea posible de justicia. La historia del derecho demuestra que la obra iluminada de los jueces puede producir una gradual renovación y perfeccionamiento del sistema vigente, aun a falta de reformas formales, sobre lo cual es inútil extendernos aquí.

Las consideraciones precedenies llevan a concluir que el llamado "derecho a la revolución" no puede ser admitido, aun bajo el aspecto ético y racional, sino con muchas restricciones y reservas. No es, sin embargo, de excluirse absolutamente como ultima ratio, cuando las leyes positivas conculquen, sin posibilidad de otro remedio, los principios fundamentales de la razón jurídica natural. En la hipótesis extrema, no puede negarse la licitud de una resisiencia contra aquellos monstra legum (para usar una frase viquiana), esto es, de una lucha para hacer valer las exigencias esenciales e inabolibles de la conciencia humana. Es racional y éticamente legitimo, entonces, lo que Locke llamó "llamado al cielo" (appeal to heaven), o sea aquella afirmación de la validez de las leyes divinas sobre las humanas, que fue expresada ya con las famosas palabras de Antígona en la tragedia de Sófocles, y desde entonces repetida más de mil veces en el iranscurso de los siglos. 